\title{
Neuroendocrine Testicular Tumors: A Systematic Review and Meta-Analysis
}

\author{
Mseddi M. Amine ${ }^{a} \quad$ Bouzguenda Mohamed $^{b} \quad$ Hadjslimane Mourad ${ }^{a} \quad$ Hamza Majed $^{a}$ \\ Charfi Slim ${ }^{c}$ Bouassida Mehdia Mnif Helac Rebai Nouria Kallel Rim ${ }^{c}$ \\ Boudaouara Tahyac Mhiri M. Nabila

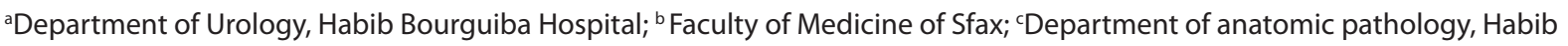 \\ Bourguiba Hospital, Sfax, Tunisia
}

\section{Key Words}

Testicular cancer • Neuroendocrine tumors • Meta-analysis

\begin{abstract}
Purpose: The purpose of this study is to study the main epidemiological, clinical, para clinical, pathological, therapeutic, and evolutionary features of patients with testicular neuroendocrine tumors (TNET). Materials and Methods: Nine case series and sixteen case reports were identified by searching PubMed database and qualified for inclusion in this study. We added the data of one case treated in the department of urology in Habib Bourguiba Hospital in Sfax, to the published cases. Results: A total of 132 cases were collected. Median age at diagnosis was 39 years old (range 1083 years). The most common presenting symptom was either a testicular mass or a swelling in $38.46 \%$ of cases. Carcinoid syndrome was documented in $10.60 \%$ of patients. The clinical examination revealed a palpable mass in $44.70 \%$ of patients. This mass was painless and firm in most cases. Serum tumor markers ( $\beta$-gonadotrophine chorionique humaine, a-feto protein, and lactate dehydrogenase) were within normal limits in all patients except in one case. Most testicular neuroendocrine tumors (76.52\%) were primary and pure.
\end{abstract}

\section{KARGER}

Fax +4161306 1234

E-Mail karger@karger.ch

www.karger.com
(C) 2016 S. Karger AG, Basel

Accessible online at: www.karger.com/cur
The tumors were positive for chromogranin (100\%), synaptophysin (100\%) and cytokeratin (93.10\%). Metastases were detected at time of diagnosis in eight cases (6.06\%). The main treatment was radical orchiectomy performed in 127 patients (96.21\%). The 5-year overall survival rate was $78.70 \%$ and the 5 -year specific survival rate was $84.30 \%$. Conclusion: The diagnosis of testicular carcinoids is based on the immunohistochemistry study. The treatment of choice for these tumors is radical orchiectomy. Somatostatin analogues were reported to be effective in patients with carcinoid syndrome.

Copyright $\odot 2016$ S. Karger AG, Basel

\section{Introduction}

Neuroendocrine tumors (NETs) consist of a spectrum of malignancies that can arise from neuroendocrine cells throughout the body. These tumors, commonly called carcinoid tumors, are characterized by their ability to produce peptides that cause characteristic hormonal syndromes [1]. 

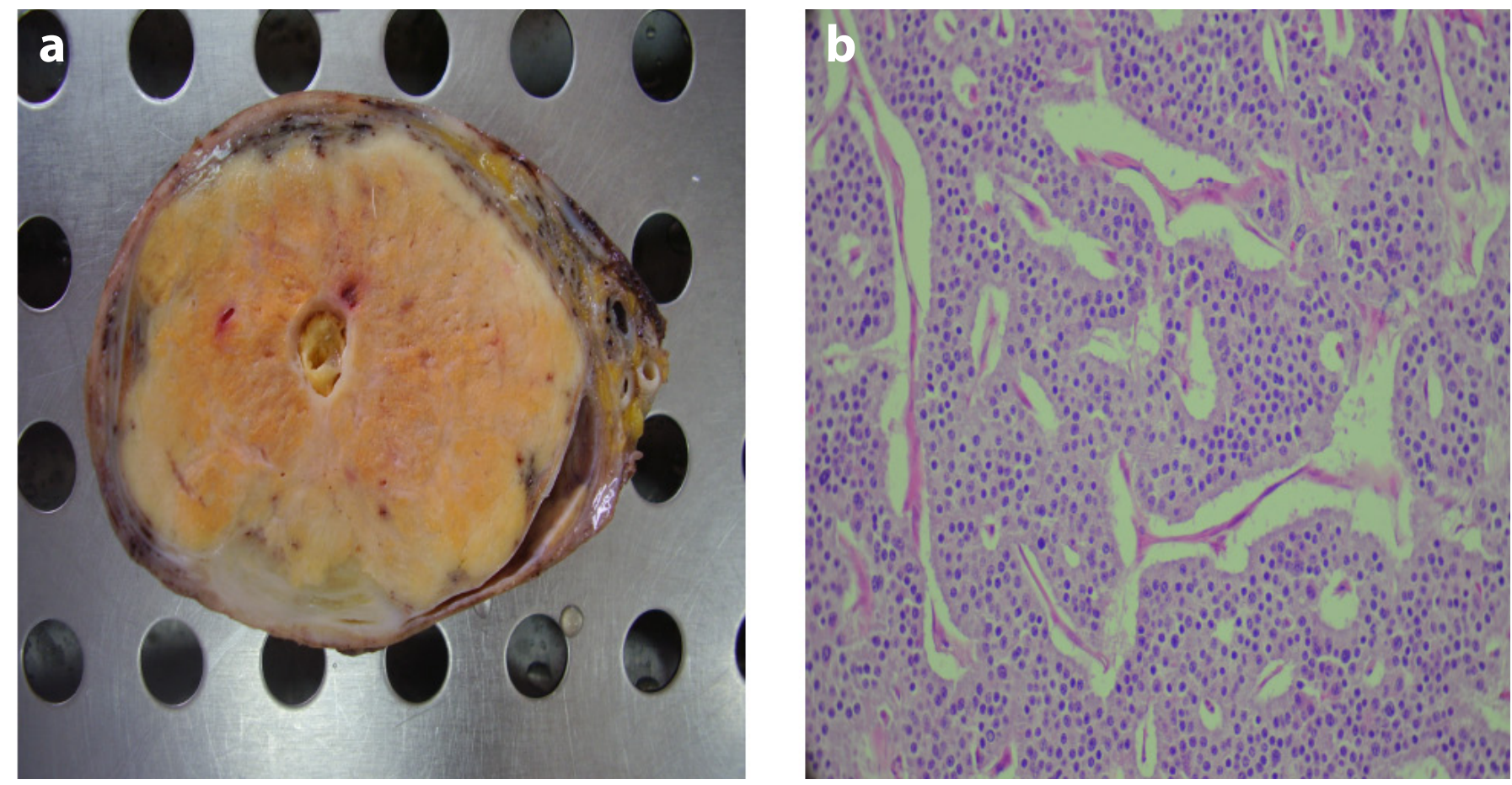

Fig. 1. a The left testis was almost replaced by a well-defined, yellow-tan, non-capsulated mass containing a small-calcified cyst. b Neoplastic cells arranged in a nesting and trabecular pattern with a background of fibrous stroma with typical rosette formation.

Among these tumors, $85 \%$ occur in the gastrointestinal tract, mostly in the ileum and appendix, and other sites, including the lungs, pancreas, biliary tract, thymus, ovary and rarely testis [2]. Testicular neuroendocrine tumors (TNET) account for less than $1 \%$ of all testicular neoplasms [3].

The aim of this meta-analysis is to study the main epidemiological, clinical, paraclinical, pathological, therapeutic, and evolutionary features of these rare tumors through the study of a testicular neuroendocrine tumor treated in the department of urology, Habib Bourguiba Hospital in Sfax as well as the study of other testicular neuroendocrine tumors cases published in the literature.

\section{Materials and Methods}

We drew up an inventory of reports and case series of patients with a testicular neuroendocrine tumor. All published studies from 1930 to 2015, either in English or French, which reported testicular neuroendocrine tumors (TNET) were reviewed and adequate information was included in this study. We also assessed the data obtained from our experience (one case). Published reports were identified through a Pubmed database search up to February 2015. The following search criteria were included: neuroendocrine, car- cinoid, carcinoid tumor, carcinoid tumors, neuroendocrine carcinoma, testicular, testicular cancer and testicular cancers. The following information was extracted from the data made available for the study: year of publication, patient characteristics, diagnostic delay, tumor type, tumor size, symptoms, diagnostic tools used, pathologic features, treatment, follow-up and survival status. Data analysis was performed with descriptive statistics and 5-year survival curves were calculated by the Kaplan-Meier method.

The present case was a 41-year-old man with a history of painful swelling of the left testis mass for 2 months. The patient did not suffer from any other discomfort. Physical examination revealed a minimally tender, firm left testicular mass of $9 \mathrm{~cm}$. The size of the right testis was normal. Tumor markers including $\beta$-gonadotrophine chorionique humaine ( $\beta \mathrm{hCG}$ ), $\alpha$-feto protein (AFP), and lactate dehydrogenase (LDH) were within normal limits.

The patient underwent an uncomplicated left radical orchiectomy. On gross examination, the left testis was almost replaced by a well-defined, yellow-tan, non-capsulated mass measuring about $10 \times 9 \times 4 \mathrm{~cm}$ and containing a small-calcified cyst of $1.2 \mathrm{~cm}$. On histological examination, the neoplastic cells were arranged in a nesting and trabecular pattern with a background of fibrous stroma with typical rosette formation (fig. 1). The cells had eosinophilic cytoplasm and round to oval nuclei centrally located with finely granular chromatin. Mitotic figures were rare $(<1$ mitotic figure per 10 high-power field), the Ki-67 labeling index of the tumor cells was less than $1 \%$ and tumor necrosis was absent. No teratomatous elements or other germ cell components were identified. 


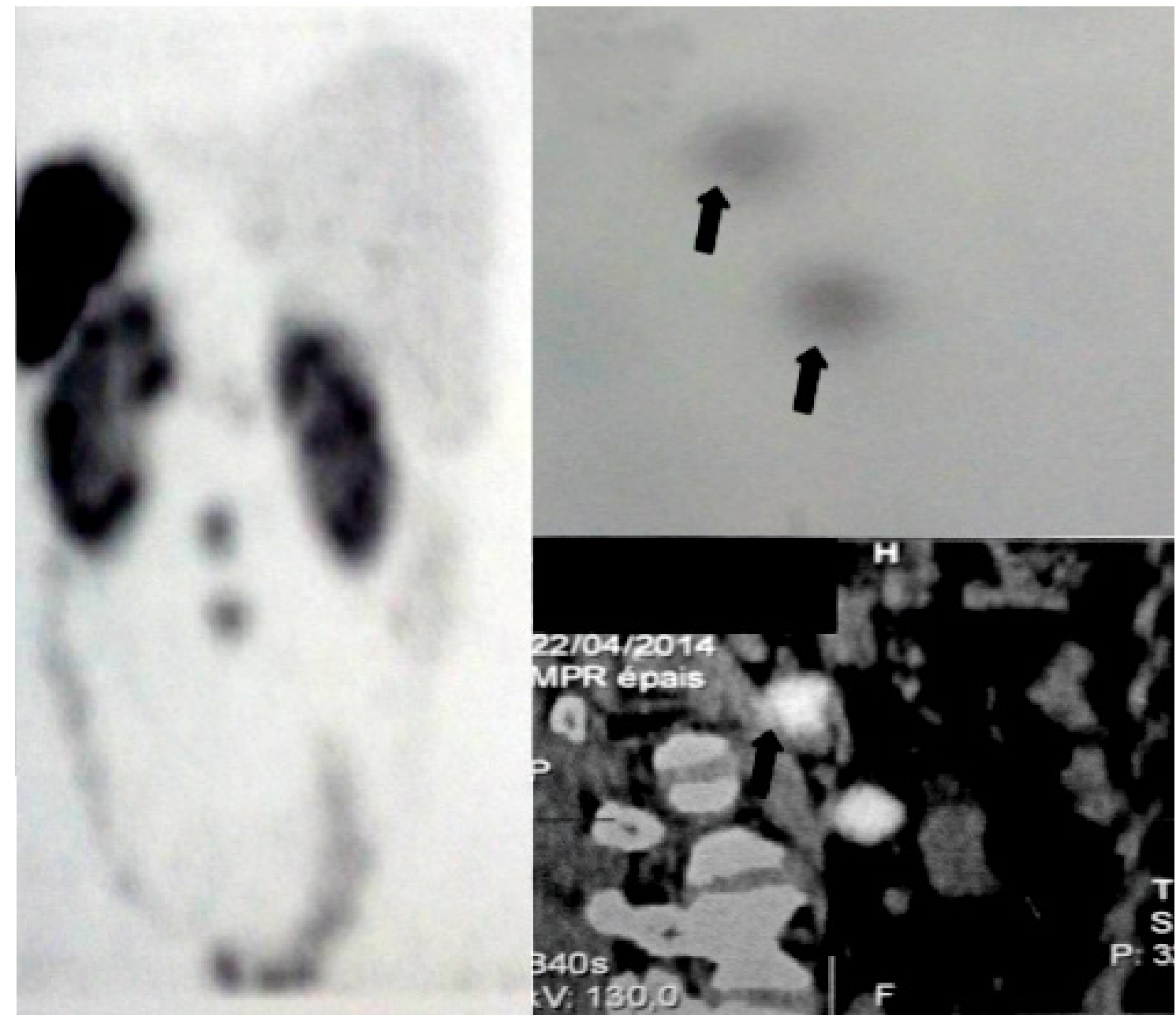

Fig. 2. Octreotide scintigraphy showing two subtle foci of activity towards the abdomen corresponding to the two para-aortic lymph nodes.

A thorough sampling of the adjacent grossly normal testicular parenchyma showed only atrophic seminiferous tubules with evidence of neither intratubular germ cell neoplasia (ITGCN) nor vascular invasion. The tunica albuginea, the epididymis and the spermatic cord were free of tumor. Immunohistochemistry expression of CD56, synaptophysin, and chromogranin A were strongly positive in the tumor cells. A well-differentiated testicular neuroendocrine tumor was diagnosed.

An extensive investigation, in order to find any evidence of a primary tumor in other locations, was carried out. It included a normal esophago-gastro-duodenoscopy, colonoscopy and a thoracic/abdominal CT. A thoracic/abdominal CT was performed a year after orchiectomy revealing two left para-aortic lymph nodes (21.6 and $19.8 \mathrm{~mm}$ in size). Octreotide scintigraphy showed two subtle foci of activity towards the abdomen corresponding to the 2 para-aortic lymph nodes (fig. 2). RPLND was performed and the metastatic lesion was resected. At 2-year follow-up the patient is asymptomatic and without signs of disease recurrence.

\section{Meta-Analysis}

Between 1930 and February 2015, 78 articles (69 case-reports and 9 case series), dealing with 140 cases of testicular neuroendocrine tumors, were published in literature. In addition to our case, we were able to access 131 cases [3-43]. Therefore, a total of 132 cases were included in the study.

Patients ranged in age from 10 to 83 years (average 39 years). The tumor predominantly occurred in men in their third and fourth decade. The left testis was affected in 50 cases $(38.64 \%)$, the right testis in 44 cases $(33.33 \%)$ and the affected side was not specified in 35 cases $(26.52 \%)$. Only 2 cases $(1.25 \%)$ of bilateral tumors have been described in the literature. 
Table 1. Distribution of testicular neuroendocrine tumors according to their type

\begin{tabular}{lll}
\hline Tumor type & Number of cases & Rate \\
\hline Pure primary TNET & 101 & $76.52 \%$ \\
TNET associated teratoma & 22 & $16.67 \%$ \\
Secondary TNET & 9 & $6.82 \%$ \\
Total & 132 & $100 \%$ \\
\hline
\end{tabular}

TNET $=$ Testicular neuroendocrine tumors

Table 2. Size of testicular neuroendocrine tumors

\begin{tabular}{lll}
\hline Tumor type & Size $(\mathrm{mm})$ & Mean size $(\mathrm{mm})$ \\
\hline Pure primary TNET & $3-110$ & 41.75 \\
TNET associated with teratoma & $10-80$ & 36.91 \\
Secondary TNET & $5-60$ & 22.13 \\
Primary TNET associated with & $5-100$ & 52.70 \\
metastases & & \\
All TNET & $3-110$ & 38.34 \\
\hline
\end{tabular}

TNET $=$ Testicular neuroendocrine tumors

Table 3. Results of immunohistochemistry study

\begin{tabular}{llll}
\hline Marker & Number of patients & Positive cases & Rate \\
\hline Cytokeratin & 29 & 27 & $93.10 \%$ \\
Chromogranin & 59 & 59 & $100 \%$ \\
Synaptophysin & 45 & 45 & $100 \%$ \\
PLAP & 20 & 0 & $0 \%$ \\
Serotonin & 15 & 13 & $86.67 \%$ \\
NSE & 14 & 14 & $100 \%$ \\
p53 & 11 & 0 & $0 \%$ \\
CD56 & 7 & 7 & $100 \%$ \\
Vimentin & 6 & 5 & $83.33 \%$ \\
Inhibin & 4 & 0 & $0 \%$ \\
TTF 1 & 3 & 1 & $33.33 \%$ \\
AFP & 2 & 0 & $0 \%$ \\
\end{tabular}

PLAP $=$ Placental alkaline phosphatase, NSE $=$ neuron specific enolase, $\mathrm{TTF}=$ thyroid transcription factor, $\mathrm{AFP}=\alpha$-feto protein.

The presenting symptoms described were a painless scrotal mass or swelling in 51 patients $(38.64 \%)$, a scrotal pain or testicular painful mass in 23 cases $(17.42 \%)$, an isolated carcinoid syndrome (flush, chronic diarrhea, abdominal pain, bronchospasm, sweats) in 4 cases (3.03\%), painless testicular mass associated with carcinoid syndrome in 6 cases $(4.55 \%)$ and a painful testicular mass associated with carcinoid syndrome in 4 cases $(3.03 \%)$. The tumor was discovered in other circumstances (hydrocele, inguinal mass, skin metastases, incidental finding) in 44 cases $(33.33 \%)$.

Serum tumor markers $\beta \mathrm{hCG}, \mathrm{AFP}$, and $\mathrm{LDH}$ were within normal limits in all 44 patients where these markers were measured except in one case of testicular neuroendocrine tumor associated with mature teratoma and para-aortic lymph nodes where the LDH level was elevated to $798 \mathrm{IU} / \mathrm{L}$. The 5-hydroxyindoleacetic acid (HIAA) values were measured in 50 patients; they were elevated in only 12 patients (24\%). These values were obtained before orchiectomy only in four patients.

Various diagnostic tools were used; preoperative scrotal ultrasonography was performed only in 37 patients (28.03\%), preoperative abdomen/pelvic CT was performed in 5 patients and pelvic MRI for diagnostic purposes was performed in only 2 patients.

In order to stage the tumor, abdominal ultrasound was performed in 2 patients. It revealed multiple target-like liver lesions in one patient and was normal in our patient. Para-aortic lymph nodes were detected in 4 patients and suspicious lymph nodes were found in the epigastric region in one patient. Liver metastases revealed as hypodense lesions were visible in 2 patients. Bone scan revealed metastases in one patient. A thoracic/abdominal/pelvic MRI was conducted in one case and showed no abnormalities. In another case, an abdominal MRI was performed towards the presence of subtle foci of activity detected by Octreotide scan; MRI confirmed that they were simple cysts. Cardiac MRI showed myocardial metastases in one patient. Octreotide scintigraphy was performed in only 11 patients $(8.33 \%)$. It was conducted before the orchiectomy in 3 patients. In one case, scintigraphy was performed in order to stage a cecal carcinoid tumor and showed no abnormal uptake. The 2 other patients had bilateral testicular neuroendocrine tumors and showed increased uptake foci in both testes. The Octreotide scintigraphy was performed postoperatively in 8 patients. It was normal in five. For the other 3 patients, it showed increased uptake subtle foci of activity towards the dome of the right lobe of the liver, increased activity in the right lower quadrant of the abdomen and 2 subtle foci of activity towards the abdomen corresponding to the two para-aortic lymph nodes. Metaiodobenzylguanidine scintigraphy was performed after orchiectomy 
Table 4. Patients treated with adjuvant chemotherapy

\begin{tabular}{|c|c|c|c|c|c|}
\hline Authors & Tumor type & Lymph node metastases & Visceral metastases & Chemotherapy protocol & Complications \\
\hline Kim Jae [10] & TNET associated with teratoma & $\begin{array}{l}\text { para-aortic and at the psoas } \\
\text { muscle region }\end{array}$ & - & three courses of BEP & $\begin{array}{l}\text { leukocytopenia and } \\
\text { skin color change }\end{array}$ \\
\hline Ingrid [11] & $\begin{array}{l}\text { primary neuroendocrine tumor } \\
\text { of the lung }\end{array}$ & para-aortic and mediastinal & testis and liver & salvage chemotherapy & - \\
\hline
\end{tabular}

TNET $=$ Testicular neuroendocrine tumors BEP $=$ bleomycin, etoposide, cisplatin .

Table 5. Patients treated with adjuvant radiotherapy

\begin{tabular}{lllll}
\hline Authors & Tumor type & Lymph node metastases & Visceral metastases & Radiation protocol \\
\hline Matthias [6] & pure primary TNET & para-aortic and epigastric & bone (sacrum) and heart & 50 gray to the sacrum \\
Nguyen [42] & pure primary TNET & - & - & 40 gray: inguinal, iliac and para-aortic nodes \\
Hosking [42] & pure primary TNET & para-aortic and mediastinal & liver and lung & 45 gray: inguinal, iliac and para-aortic nodes \\
\hline
\end{tabular}

TNET $=$ Testicular neuroendocrine tumors.

in 2 patients and showed no abnormal uptake. Positron emission tomography (PET) with fludeoxyglucose F 18 was conducted in one patient showing enlarged lymph nodes in the para-aortic and the psoas muscle area. Two patients underwent PET-scan; it revealed lymph node metastases, retroperitoneal para-aortic bilateral osseous metastases in the area of the sacrum (sacral vertebra), as well as an intra-myocardial metastasis in one case while it was negative in the other case.

To confirm the absence of a digestive neuroendocrine tumor, upper-gastrointestinal series were performed in 19 patients, small bowel follow-through in 17 patients and barium enema in 6 patients. These tests were all normal. Upper gastrointestinal tract pan-endoscopy was conducted in 4 cases and showed no abnormality. Colonoscopy was performed in 5 patients; it showed no suspicious lesion in 3 cases, nodular mucosal elevation in the terminal ileum in one case and revealed a carcinoid of the terminal ileum near the ileo-cecal valve in the last case.

TNET can be divided into pure primary neuroendocrine tumors, testicular metastasis from another location and neuroendocrine tumors associated with a testicular teratoma (table 1).

Secondary testicular neuroendocrine tumors were metastasis from gastrointestinal neuroendocrine tumors in 8 cases $(88.89 \%)$.

Neuroendocrine Testicular Tumors
The mean size of all TNET was $38.34 \mathrm{~mm}$ while primary testicular carcinoids associated with metastases had a mean size of $52.70 \mathrm{~mm}$ (table 2).

We have data on macroscopic examination of 105 tumors. The tumor was firm, homogeneous, well circumscribed in most cases $(94.29 \%)$. Necrotic zones were present in 9 tumors, hemorrhagic areas were visible in 8 and calcifications were found in 19. The tumor was encapsulated in 5 cases. Neuroendocrine tumors testicular were "typical carcinoids" in the vast majority of cases (88.64\%), only 15 cases could be considered as "atypical carcinoids". Several growth patterns were reported. The predominant growth pattern was the insular pattern observed in $94.50 \%$ of tumors. Trabecular, pseudo-glandular and nested pattern were also observed. The presence of vascular invasion was rare, and it was observed in 10 cases only. ITGCN was identified only in 2 cases. The teratoma associated with TNET were mature in 15 patients, epidermoid cysts in 4 patients, dermoid cyst or immature teratoma in a single case for each. The Fontana-Masson stain was performed in 36 patients and revealed argentaffin granules in 34 patients. Grimelius stain was performed in 18 patients and detected argyrophilic granules in all of them. Results of the immunohistochemistry study (available for 59 patients) of neuroendocrine markers, amine and polypeptide hormones are in table 3 . 


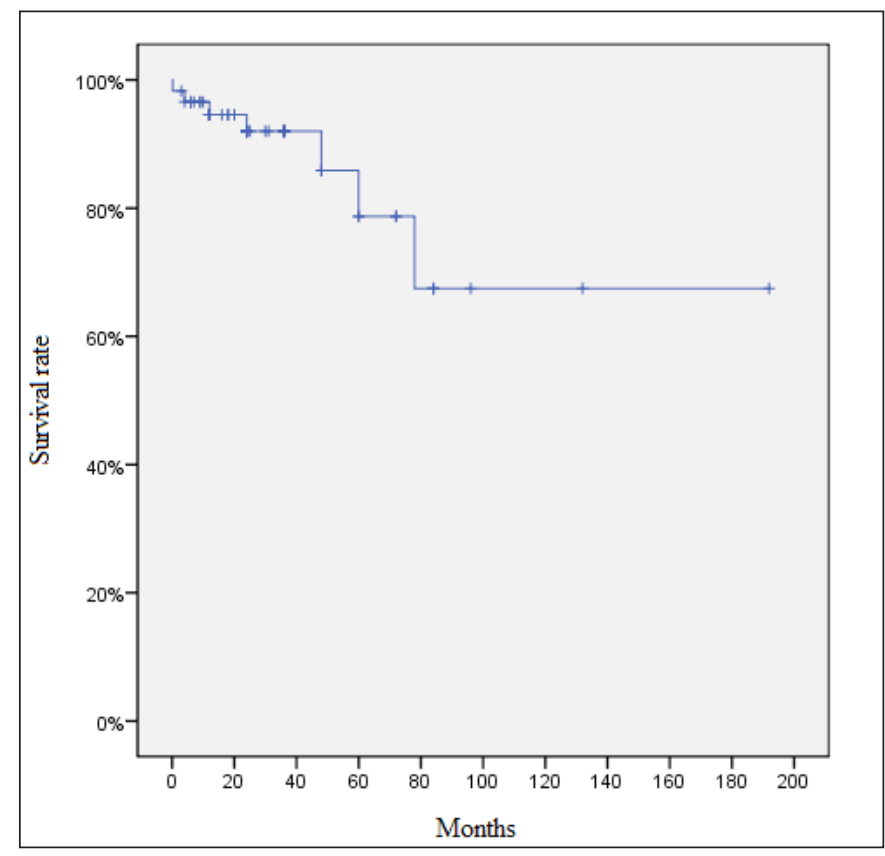

Fig. 3. 5-year overall survival curve.

Para-aortic lymph node metastases were documented in 12 patients $(9.09 \%)$. Eight patients $(6.06 \%)$ with pure primary testicular neuroendocrine tumors presented visceral metastases while no patient with carcinoid tumor associated with teratoma has developed visceral metastases. The most affected organ was the liver in four cases.

Regarding the treatment of these tumors, 127 patients (96.21\%) underwent a radical orchiectomy and only 3 patients $(2.27 \%)$ with epidermoid cysts had a focal excision. In a single case, the radical orchiectomy was preceded by a surgical biopsy and another case was an incidental finding at autopsy. A retroperitoneal lymph node dissection (RPLND) was done in seven patients with lymph node metastases and in a patient having a TNET associated with a teratoma without demonstrable lymph node metastases. In one case, an mRPLND was performed. Neoadjuvant chemotherapy was not performed in any patient having a testicular neuroendocrine tumor. Three patients $(2.27 \%)$ were treated with adjuvant chemotherapy as described in table 4 . Chemotherapy generated no response on the size of metastatic lymph nodes in two patients and the response to the treatment was not reported in the third patient with primary neuroendocrine tumors of the lung.

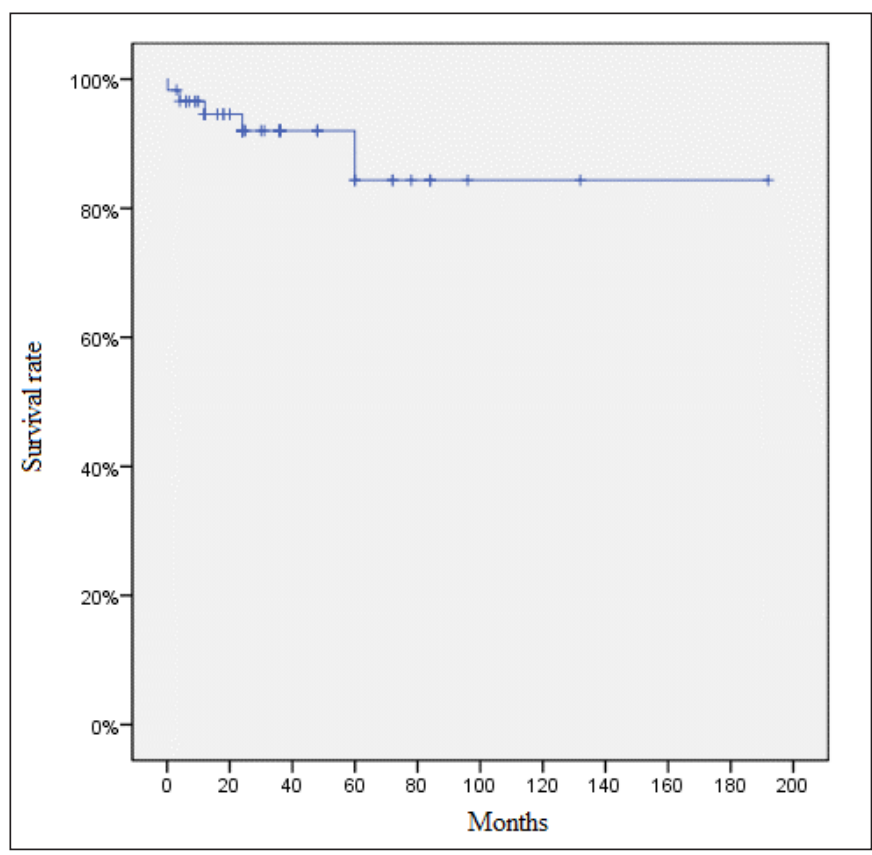

Fig. 4. 5-year specific survival curve.

Neoadjuvant radiotherapy has not been used in any patient with neuroendocrine tumor testicular. Three patients $(2.27 \%)$ with pure primary testicular neuroendocrine tumors received adjuvant radiotherapy without obvious complications (table 5).

Three patients received somatostatin analogues. The first patient with cecal neuroendocrine tumor has received "Octreotide" and low-dose $\alpha$-interferon 30 months after right hemicolectomy before the beginning of symptoms of carcinoid syndrome. After treatment, these symptoms regressed but a neuroendocrine right testicular tumor was discovered several months later. The second patient had a pure primary testicular neuroendocrine tumor with lymph node, bone and heart metastases. Due to the impossible curative treatment of cardiac metastases and the suspected somatostatin receptor within, the patient received "lanreotide: $60 \mathrm{mg}$ every 4 weeks". Five months later, PET/CT and cardiac MRI led to a stable disease. The effect of treatment with Octreotide in the third patient (having a secondary TNET of ileal origin) was not specified.

The 5-year overall survival rate was $78.70 \%$ (fig. 3) while the 5 -year specific survival rate was $84.30 \%$ (fig. 4). 


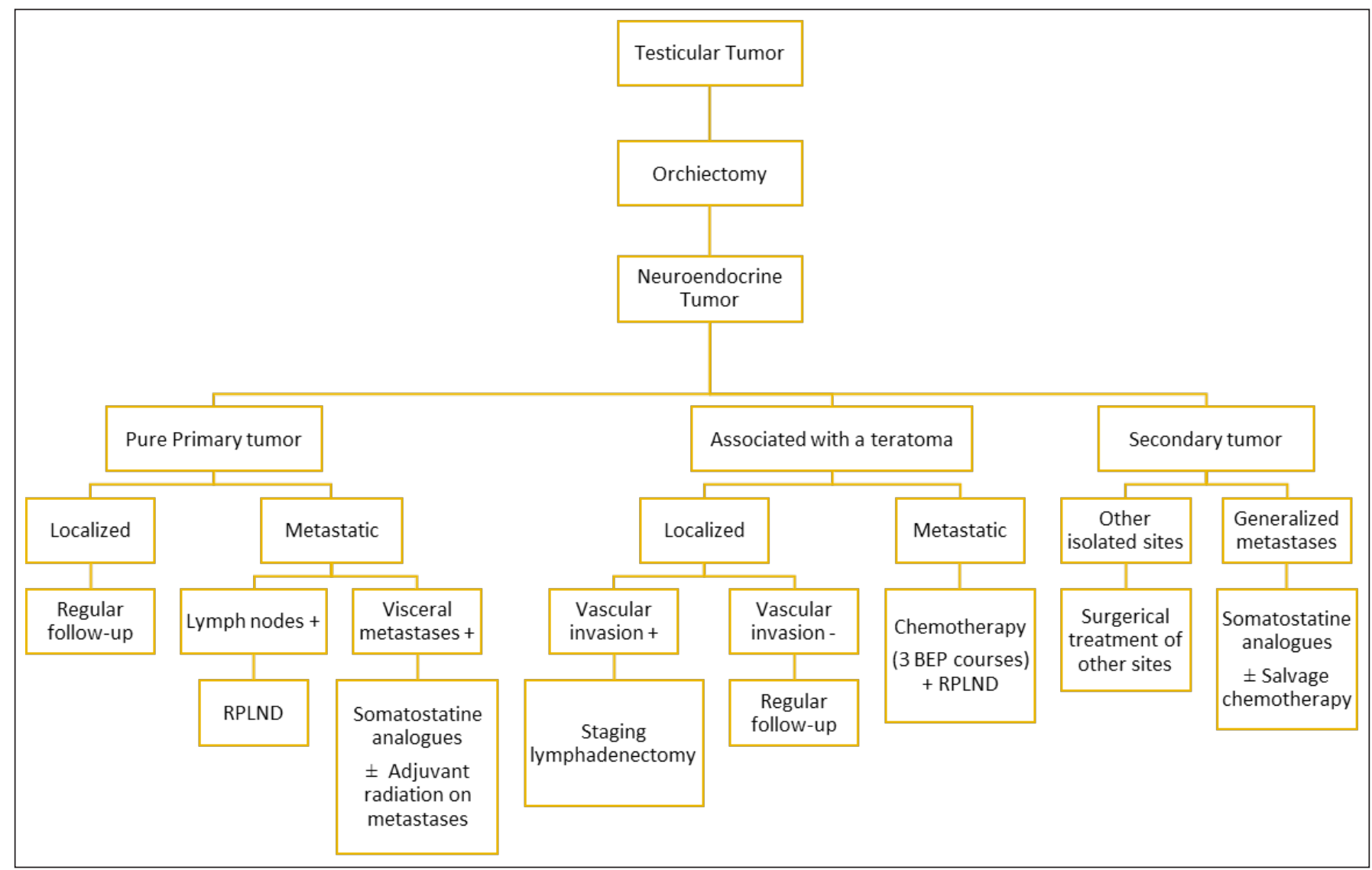

Fig. 5. Tumors of neuroendocrine testicular Treatment: decision tree.

\section{Discussion}

Primary TNETs are rare. They represent less than $1 \%$ of all testicular neoplasms [3]. The most sizeable review was conducted by Stroosma [42], and it included 62 published cases of carcinoid tumors of the testis between 1930 and 2006. In this meta-analysis, we studied 132 cases of neuroendocrine testicular tumors.

TNET appears to be a young man's cancer (mean age $=39$ years and peak incidence $=30-40$ years) but may occur in children as in the elderly (age range 10-83 years). The mean age was higher in patients with secondary TNET (55.44 years) compared to patients with pure primary TNET or associated with teratoma (41.43 and 38.5 years respectively). In this meta-analysis, the tumors were almost equally distributed over the left and right side with a slight tropism for the left testicle. TNET is usually painless and consequently does not attract the patient attention $[3,42]$. Therefore, it is common to note a significant delay between the discovery by the patient of a testicular swelling and the first consultation. Other symptoms include a painful testis, hydrocele, undescended testis, and carcinoid syndrome. Carcinoid syndrome is quite rare [42] and usually occurs late in the course of the disease, almost always in metastatic forms. In this meta-analysis, $10.60 \%$ of the patients had symptoms of carcinoid syndrome, which is lower than the $16 \%$ and $12.28 \%$ reported previously Stroosma et al. [42] and Zavala-Pompa et al. [43] respectively. TNETs do not cause an increase in the serum level of typical markers of testicular tumors (AFP, $\beta$-HCG, LDH). However, they may cause an increase in the serum level of neuroendocrine tumors markers such as NSE, the vanillylmandelic acid, the serum serotonin and its main urinary metabolite, 5-HIAA measured in a 24-h urine sample. Only $88 \%$ of all carcinoid tumors produce 5-HIAA $\mu$ [44]. 
Among diagnosis tools, scrotal ultrasonography is currently the gold standard in term of morphological examination of testis. Regarding neuroendocrine tumors of the testis, it usually reveals dense punctate calcifications within a well-defined solid hypoechoic mass [21, 25]. Pelvic CT has an essential role in the staging of testicular neuroendocrine tumors and in the diagnosis of tumors in undescended testis [10]. Neuroendocrine testicular tumor appear as a T2 hypo intense nodule in MRI [14]. However, the role of MRI in the diagnosis is very limited [45]. Somatostatin receptor scintigraphy with Octreotide has a sensitivity that varies from ranges from 70 to $90 \%$ in the detection of primary neuroendocrine tumors [46]. Metaiodobenzylguanidine scintigraphy has a lower sensitivity $(50 \%)$ than somatostatin receptor scintigraphy [47].

Neuroendocrine tumors of the testis can be divided into 3 categories: pure primary testicular neuroendocrine tumors, secondary neuroendocrine tumors and those associated with testicular teratoma. Testicular neuroendocrine tumor associated with teratoma is a distinct disease entity where the clinical course, treatment and prognosis are similar to those of testicular teratoma [40]. In this meta-analysis, most testicular neuroendocrine tumors $(76.52 \%)$ were primary and pure.

A difference in size exists between pure primary TNET and TNET associated with teratoma. The mean size of carcinoids associated with teratoma $(36.91 \mathrm{~mm})$ was lower than those pure $(41.75 \mathrm{~mm})$. Furthermore, TNET with metastatic lymph nodes or visceral metastases had a larger size (mean size $=52.70 \mathrm{~mm}$ ) than non-metastatic tumors (mean size $=35.26 \mathrm{~mm}$ ) which is coherent with the results reported by Stroosma et al. [42] and ZavalaPompa et al. [43] in their literature reviews. Tumors of large size may present necrotic zones and have a higher probability of developing carcinoid syndrome [21,30].

Wang et al. [3] used the morphological classification of the WHO of pulmonary neuroendocrine tumors published in 1999 [48] to divide the TNET into typical carcinoid and atypical carcinoid tumors. According to our meta-analysis, testicular neuroendocrine tumors were "typical carcinoid" in $88.64 \%$ of cases; these tumors were composed of monomorphous polygonal shaped cells with modest amounts of eosinophilic cytoplasm and uniform bland nuclei with finely dispersed chromatin [3, 20]. ITGCN were found in only two cases of neuroendocrine testicular tumor published [20,27]. The only case of pure primary TNET associated with ITGCN lesions is the key of the theory assuming the germ cell origin of these tumors [27].
Neuroendocrine tumors are characterized by the presence argentaffin and argyrophilic cells [49]. In this meta-analysis, the tumor cells were both argentaffin and argyrophilic in all cases, except in two cases where the tumor was argyrophilic but not argentaffin. The histological diagnosis of TNET is usually straightforward. Immunohistochemistry study will lead to the correct diagnosis. In this meta-analysis, TNETs were positive for cytokeratin, chromogranin, synaptophysin, serotonin, NSE, vimentin and CD56 at a rate greater than $80 \%$ while immunostaining for PLAP, p53, AFP and inhibin were negative.

We recommend performing a thoracic/abdominal/pelvic CT-scan, Octreotide scintigraphy and digestive pan endoscopy to establish a full tumor staging and exclude a possible primary tumor. CT scan is the gold standard in the detection of lymph node and visceral metastases of urogenital tumors [50]. MRI is rarely used in the staging of testicular tumors since it provides the same morphological information as CT-scan regarding the detection of lymph node metastases [45]. Octreotide scintigraphy allows the examination of the entire body with significantly higher performance than CT or ultrasound. It is indicated in the diagnosis, staging and primary site exclusion [51]. This imaging technique is superior to $\mathrm{CT}$ in the detection of the primary tumor's site and has a sensitivity that varies between $80-96 \%$ depending on the series to detect visceral metastases [4,17]. The use of PET scan with 18-fludeoxyglucose is limited because of their low proliferative activity [52]. Although not used in any of the cases reported here, promising results using the 18F-dopa PET have been described for the detection of small neuroendocrine tumors and lymph node metastases with a reported sensitivity that ranged from $65 \%$ to $100 \%$ [53, 54]. Video-capsule endoscopy, a recent development in intestinal imaging, has proved its efficiency in the staging of carcinoid tumors and in the localization of digestive primary tumors, although not used in any of the cases described in our meta-analysis $[52,55]$.

In our meta-analysis, 12 patients $(9.09 \%)$ had developed lymph node metastases and eight patients $(6,06 \%)$ had visceral metastases. The most affected organ in this meta-analysis was the liver in four patients, which is consistent with the literature review of Stroosma et al. [42] where the liver was the most affected site.

Radical inguinal orchiectomy with close follow-up is the treatment of choice for testicular neuroendocrine tumors [42]. However, a key point to be made is that the treatment of testicular neuroendocrine tumor associated with teratoma is identical to that of testicular ter- 
atoma [56]. The indications of RPLND in pure primary testicular neuroendocrine tumor remain unclear. In our meta-analysis, among the eight patients who had pure primitive testicular neuroendocrine tumors with lymph node metastases only four patients underwent lymph node dissection. Still, all patients who had conducted a retroperitoneal lymphadenectomy had lymph node metastases. Complementary treatments of testicular neuroendocrine tumor include chemotherapy, radiotherapy, somatostatin analogues and -Interferon. The standard protocol of adjuvant chemotherapy for metastatic neuroendocrine tumors includes streptozocin, 5-FU and cyclophosphamide or doxorubicin. This protocol generated short lasting responses in less than $10 \%$ of patients [57]. Radiotherapy had shown little effect on metastatic neuroendocrine tumors $[2,10,52]$. Octreotide, a somatostatin analogue, can induce symptomatic improvement in $80 \%$ of patients with metastatic neuroendocrine tumors [52]. Besides the improvement of symptoms, the somatostatin analogs can stop tumor growth. This is the result of a meta-analysis including 28 trials on the effect of somatostatin analogues in neuroendocrine tumors. In this study, stable disease rates were between $15 \%$ and $89 \%$ [58]. The interferon has been used in only one patient in our meta-analysis in association with Octreotide. This patient showed clinical response but developed testicular metastases later. Somatostatin analogues (octreotide, lanreotide) and interferon- can be indicated in patients with carcinoid syndrome where they have proven their efficiency $[42,52]$. They can also be prescribed for patients with metastatic neuroendocrine testicular tumors to stabilize disease progression $[6,58]$. After this literature review and this meta-analysis, we established a treatment algorithm of testicular neuroendocrine tumors (fig. 5).

Neuroendocrine tumors can metastasize up to 17 years after the initial treatment [35]. Hence, we need a regular and long-term follow-up. The follow-up strategy is a matter of debate and follow-up data is insufficient to conclude a well-defined protocol [42].

To sum up, the prognosis of testicular neuroendocrine tumor is good [3, 42]. In our meta-analysis, the 5-year overall survival rate was $78.70 \%$ and the 5 -year specific survival rate was $84.30 \%$. The poor prognostic factors include large tumor size, low-degree of tumor differentiation and the presence of a carcinoid syndrome $[6,15$, 43]. The prognosis of TNET associated with a teratoma seems to be better than pure testicular neuroendocrine tumor $[13,43]$. In our meta-analysis, there was no death or visceral metastasis development in patients with TNET associated with testicular teratoma.

\section{Conclusion}

Testicular neuroendocrine tumors represent an issue that seems far away from having revealed all its secrets. These tumors are rare but have a good prognosis. The diagnosis is based on the immunohistochemistry study. The primary nature of the tumor can be retained only after excluding a secondary origin mainly in the gastrointestinal tract or in lungs. Radical orchiectomy is the treatment of choice for testicular neuroendocrine tumor. Somatostatin analogues were reported to be effective in patients with carcinoid syndrome and can stabilize metastatic disease progression. 


\section{References}

1 Yao JC, Hassan M, Phan A, Dagohoy C, Leary C, Mares JE, Abdalla EK, Fleming JB, Vauthey JN, Rashid A, Evans DB: One hundred years after "carcinoid": epidemiology of and prognostic factors for neuroendocrine tumors in 35,825 cases in the United States. J Clin Oncol 2008;26:3063-3072.

2 Modlin IM, Latich I, Kidd M, Zikusoka M, Eick G: Therapeutic options for gastrointestinal carcinoids. Clin Gastroenterol Hepatol 2006;4:526-547.

3 Wang WP, Guo C, Berney DM, Ulbright TM, Hansel DE, Shen R, Ali T, Epstein JI: Primary carcinoid tumors of the testis: a clinicopathologic study of 29 cases. Am J Surg Pathol 2010;34:519-524.

4 Petrossian AA, Habibi J, Rapp DE, Ramnani D: Primary carcinoid tumor of the testis. Case Rep Urol 2015;2015:687482.

5 Chikkaraddi ML, Krishna S, Shetty M: Primary testicular carcinoid tumor presenting as carcinoid heart disease. Indian J Urol 2015; 31:65-67.

6 Penke M: Primary neuroendocrine tumor of the testis and osseous, cardiac, and lymph node metastases in a young patient. Case Rep Oncology 2014;7:815-818.

7 Arrigo LD, Costa A, Fraggetta F, Cacciola A, Bonaccorsi A, Savoca F, Aragona F: Primary carcinoid tumour of the testis : a case-report. Arch Ital Urol Androl 2014;86:231-232.

8 Alsharif S, Al-Shraim M, Alhadi A, Al-Aown A, Fooshang F, Eid R: Primary neuroendocrine tumor of the testis. Urol Ann 2014;6: 173-175.

9 Han X, Yu L, Yang S, Zheng J: Primary neuroendocrine tumor of the testis : a study of clinicopathological features. Int J Clin Exp Pathol 2014;7:1771-1776.

10 Kim JH, Noh T Il, Shim JS, Ham BK, Choi H, Bae JH, Park JY: Primary testicular carcinoid tumour with mature teratoma in undescended testis metastatic to lymph nodes. Can Urol Assoc J 2014;8:E245-248.

11 Birker IL, van der Zee JA, Keizer KM: Uncommon testicular metastasis of a primary neuroendocrine tumour of the lung. Can Urol Assoc J 2013;7:E614-617.

12 Suryawanshi KH, Damle RP, Dravid N V, Nikumbh DB, Tayade YR: Primary carcinoid tumour of testis - a rare case report. Int J Health Sci Res 2013;3:131-135.

13 Epperson JR, Pope NM, Abuzeid MJ: Rare testicular tumor discovered by assault : an unusual presentation of a primary testicular neuroendocrine tumor grade 2. Case Rep Pathol 2013;2013:709352.

14 Li HK, Huang EY, Lin AT, Chen KK: Testicular carcinoid tumor: acase report and literature review. Urol Sci 2013;25:143-145.

15 Lau H, Lai V: Metastatic testicular carcinoid tumour. Hong Kong J Radiol 2013;16:69-73.
16 Palla AR, Hogan T, Singh S: Unusual presentation of a left testicular carcinoid. Case Rep Oncol 2012;5:43-46.

17 Neely D, Gray S: Primary carcinoid tumour of the testis. Ulster Med J 2011;80:79-81.

18 Frederick LR, Ballek NK, Esplin JA, Köhler TS: Primary carcinoid tumor presenting as a nonpalpable testicular mass. J Clin Oncol 2010;28:e637-639.

19 Loghin A, Borda A, Decaussin-Petrucci M, Berger N: A rare testicular tumor. Ann Path 2008;28:338-340.

20 Abbosh PH, Zhang S, Maclennan GT, Montironi R, Lopez-Beltran A, Rank JP, Baldridge LA, Cheng L: Germ cell origin of testicular carcinoid tumors. Clin Cancer Res 2008;14:1393-1396.

21 Park SB, Kim JK, Cho KS: Imaging findings of a primary bilateral testicular carcinoid tumor associated with carcinoid syndrome. J Ultrasound Med 2006;25:413-416.

22 Wolf M, Wunderlich H, Hindermann W, Gajda M, Schreiber G, Schubert J: Case report: Primary carcinoid tumor of the testicle without metastases in combination with testicular atrophy and testosterone deficiency. Int Urol Nephrol 2006;38:625-628.

23 Fucs M, Romero FR, Germanos de Castro M, de Carvalho Fernandes R, Camara-Lopes LH, Cardenuto Perez MD: Testicular metastasis 10 years after resection of appendiceal carcinoid. Urology 2005;65:591.

24 Abrahamsson J, Mellander L, Nilsson O, Rubensson A: Multiple lymph node metastases in a boy with primary testicular carcinoid, despite negative preoperative imaging procedures. J Pediatr Surg 2005;40:e19-21.

25 Blumberg JM, Sedberry S, Kazmi SO: Bilateral asynchronous metastatic carcinoid tumor of the testis. Urology 2005;65:174.

26 Fujita K, Wada R, Sakurai T, Sashide K, Fujime M: Primary carcinoid tumor of the testis with teratoma metastatic to the para-aortic lymph node. Int J Urol 2005;12:328-331.

27 Merino J, Zuluaga a, Gutierrez-Tejero F, Del Mar Serrano M, Ciani S, Nogales FF: Pure testicular carcinoid associated with intratubular germ cell neoplasia. J Clin Pathol 2005; 58:1331-1333.

28 Khan SA, John G, Howell SD: Primary carcinoid tumour of the testis. J Pak Med Assoc 2005;55:561-563.

29 Xiao GQ, Birns DR, Warner RRP, Selleck W, Unger PD: Testicular metastasis of primary cecal carcinoid tumor. Ann Diagn Pathol 2004;8:102-107.

30 Son HY, Ra SW, Jeong JO, Koh EH, Lee HI, Koh JM, Kim WB, Park JY, Shong YK, Lee KU, Kim GS, Kim MS: Primary carcinoid tumor of the bilateral testis associated with carcinoid syndrome. Int J Urol 2004;11:10411043.
31 Thomas JC, Jones JS: Primary carcinoid tumor of the testis found at the time of elective sterilization. J Androl 2004;25:338-339.

32 Kato N, Motoyama T, Kameda N, Hiruta N, Emura I, Hasegawa G, Murata T, Kimura M, Tsuda H, Ishihara T: Primary carcinoid tumor of the testis: Immunohistochemical, ultrastructural and FISH analysis with review of the literature. Pathol Int 2003;53:680-685.

33 Reyes A, Moran CA, Suster S, Michal M, Dominguez $\mathrm{H}$ : Neuroendocrine carcinomas (carcinoid tumor) of the testis: A clinicopathologic and immunohistochemical study of ten cases. Am J Clin Pathol 2003;120:182_ 187.

34 Chang YH, Chuang CK, Wu CT, Ng KF, Liao SK: Primary carcinoid tumor of the testis: case report. Chang Gung Med J 2002;25: 695-699.

35 Hayashi T, Iida S, Taguchi J, Miyajima J, Matsuo M, Tomiyasu K, Matsuoka K, Noda S: Primary carcinoid of the testis associated with carcinoid syndrome. Int J Urol 2001;8: 522-524.

36 Singer AJ, Anders KH: Primary carcinoid of the testis 25 years after contralateral testicular seminoma. Urology 2001;57:554-555.

37 Kim HJ, Cho MY, Park YN, Kie JH: Primary carcinoid tumor of the testis: immunohistochemical, ultrastructural and DNA flow cytometric study of two cases. J Korean Med Sci 1999;14:57-62.

38 Glazier DB, Murphy DP, Barnard N, Cummings KB, Weiss RE: Primary carcinoid tumour of the testis. BJU Int 1999;83:153-154.

39 Kardar AH, Tulbah A, Peracha A, Merdad T, Al-Mathami A: Primary carcinoid tumor of testis. Ann Saudi Med 1997;17:223-225.

40 Monsaint H, Mikaelian JC, Arnal X, Cukier $\mathrm{J}$ : Pure primary carcinoid tumor of the testis. Apropos of a case. Prog Urol 1995;5:274275.

41 Terhune DW, Manson AL, Jordon GH, Peterson N, Auman JR, MacDonald GR: Pure primary testicular carcinoid: a case report and discussion. J Urol 1988;139:132-133.

42 Stroosma OB, Delaere KP: Carcinoid tumours of the testis. BJU Int 2008;101:11011105.

43 Zavala-Pompa A, Ro JY, El-Naggar A, Ordóñez NG, Amin MB, Pierce PD, Ayala AG: Primary carcinoid tumor of testis. Immunohistochemical, ultrastructural, and DNA flow cytometric study of three cases with a review of the literature. Cancer 1993;72:1726-1732.

44 Debas H, Orloff S: Carcinoid tumors and the carcinoid syndrome. Textbook of Surgery. ed 15. Philadelphia, Sabiston DC, 1997, pp 950-954.

45 Hubert J, Descotes JL, Martin B: Urology imaging: imaging of germ cell tumors of the testis. Prog Urol 2003;13:969-984. 
46 Cavet M, Tenenbaum F, Hignette C, Modis C, Richard B, Faraggi M, Dousset B: Recurrent carcinoid tumor and 18F-DOPA PET. Gastroenterol Clin Biol 2010;34:213-217.

47 Oberg K, Eriksson B: Nuclear medicine in the detection, staging and treatment of gastrointestinal carcinoid tumours. Best Pract Res Clin Endocrinol Metab 2005;19:265-276.

48 Brambilla E, Travis WD, Colby T V, Corrin B, Shimosato Y: The new World Health Organization classification of lung tumours. Eur Respir J 2001;18:1059-1068.

49 Eichhorn JH, Young RH: Neuroendocrine tumors of the genital tract. Am J Clin Pathol 2001;115(suppl):s94-112.

50 Correas JM, Méjean A, Hélénon O: The imaging aspects of metastases from urological malignancies. Prog Urol 2008;18(suppl 7):S196-201.
51 Müller-brand J, Forrer F: Scintigraphie à l'octréotide pour l'imagerie moléculaire des tumeurs neuroendocrines. Forum Med Suisse 2008;8:757-758.

52 Zuetenhorst JM, Taal BG: Metastatic carcinoid tumors: a clinical review. Oncologist 2005;10:123-131.

53 Jager PL, Chirakal R, Marriott CJ, Brouwers AH, Koopmans KP, Gulenchyn KY: 6-L-18F-fluorodihydroxyphenylalanine PET in neuroendocrine tumors: basic aspects and emerging clinical applications. J Nucl Med 2008:49:573-586.

54 Koopmans KP, de Vries EG, Kema IP, Elsinga $\mathrm{PH}$, Neels $\mathrm{OC}$, Sluiter $\mathrm{WJ}$, van der Horst-Schrivers AN, Jager PL: Staging of carcinoid tumours with 18F-DOPA PET: a prospective, diagnostic accuracy study. Lancet Oncol 2006;7:728-734.
55 Romero FR, Rais-Bahrami S, Permpongkosol S, Fine SW, Kohanim S, Jarrett TW: Primary carcinoid tumors of the kidney. J Urol 2006;176:2359-2366.

56 Frank RG, Gerard PS, Anselmo MT, Bennett L, Preminger BI, Wise GJ: Primary carcinoid tumor of the testis. Urol Radiol 1991;12:203205.

57 Oberg K: Chemotherapy and biotherapy in the treatment of neuroendocrine tumours. Ann Oncol 2001;12(suppl 2):S111-114.

58 Sidéris L, Dubé P, Rinke A: Antitumor effects of somatostatin analogs in neuroendocrine tumors. Oncologist 2012;17:747-755. 